\title{
Community composition of bacteria involved in fixed nitrogen loss in the water column of two major oxygen minimum zones in the ocean
}

\author{
Amal Jayakumar*, Xuefeng Peng, Bess B. Ward \\ Department of Geosciences, Princeton University, Princeton, New Jersey 08544, USA
}

ABSTRACT: The community composition of bacteria involved in nitrogen (N) transformations in the oxygen minimum zones (OMZ) may be related to the rates of fixed $\mathrm{N}$ loss in these systems. The abundance of both denitrifying and anammox bacteria and the assemblage composition of denitrifiers were investigated in the Eastern Tropical South Pacific and the Arabian Sea using assays based on bacterial molecular markers. Quantitative PCR was used to investigate the abundance and distribution of genes encoding nitrite reductase (nirK and nirS) in denitrifying bacteria and hydrazine oxidase (hzo) and 16S rRNA genes in anammox bacteria. All of these genes had depth distributions with maxima associated with the secondary nitrite maximum in low-oxygen waters. NirS was much more abundant than nirK and much more abundant than the 16S rRNA gene from anammox bacteria. The ratio of hzo:16S rRNA was low and variable, implying greater unexplored diversity in the hzo gene. Assemblage composition of the abundant nirS-type denitrifiers was evaluated using a functional gene microarray. Of the nirS archetypes represented on the microarray, very few occurred specifically in one region or depth interval, but the assemblages varied significantly. Community composition of denitrifiers based on microarray analysis of the nirS gene was most different between geographical regions. Within each region, the surface layer and OMZ assemblages clustered distinctly. Thus, in addition to spatial and temporal variation in denitrification and anammox rates, microbial abundance and community composition also vary between $\mathrm{OMZ}$ regions and depths.

KEY WORDS: Denitrifying bacteria - Oxygen minimum zone $\cdot$ Community composition

Resale or republication not permitted without written consent of the publisher

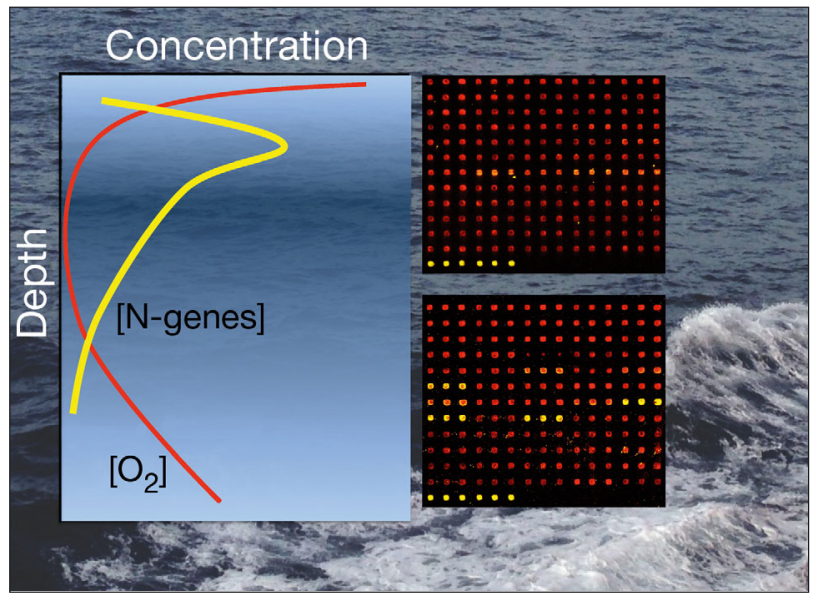

Nitrogen removal genes (yellow curve) peaked at the top of the OMZ (red curve shows $\mathrm{O}_{2}$ concentration). The nirS assemblage differed between oxic (upper array) and OMZ (lower array) waters and between oceanic regions.

Image: Bess Ward

\section{INTRODUCTION}

The Arabian Sea (AS) and the Eastern Tropical South Pacific (ETSP) ocean regions are known as oxygen minimum zones (OMZ) (Paulmier \& RuizPino 2009) because they are associated with subsurface oxygen depleted depths, in which the oxygen concentration is essentially zero (Revsbech et al. 2009). Depth intervals where oxygen is completely depleted, allowing the functioning of anaerobic microbial pathways including denitrification and anammox, can extend for hundreds of meters and are 
often referred to as the oxygen depleted zone (ODZ). Both denitrification and anammox occur in waters with oxygen concentrations below detection limits $\left(10-90 \mathrm{nM}_{i}\right.$ Dalsgaard et al. 2012). We refer to the oceanic regions as OMZs and the depth interval of essentially zero oxygen as the ODZ.

The water columns of OMZs have characteristic chemical distributions, usually including 2 nitrite maxima and 2 nitrous oxide maxima (Bange 2008, Devol 2008). In the AS, high-resolution profiles of $\mathrm{NO}_{2}{ }^{-}$and $\mathrm{N}_{2} \mathrm{O}$ show multiple maxima and minima, suggesting the interleaving of water masses with different oxygen histories (Nicholls et al. 2007). Although the distribution of the $\mathrm{N}$ loss processes is known with much lower resolution, the highest rates of anammox appear to be associated with the upper regions of the low oxygen water, just below the depth at which oxygen reaches zero levels (Bulow et al. 2010, Hamersley et al. 2007, Dalsgaard et al. 2012). Denitrification is more variable and shows no obvious depth pattern in published reports to date. In an extensive study of the coastal region of the ETSP, Dalsgaard et al. (2012) found that anammox and denitrification had somewhat opposite distributions; where one rate was high, the other was low. Thus, it is not possible at present to explain the reproducibility of the observed chemical distributions in terms of the measured $\mathrm{N}$ transformation rates. After chemistry and transformation rates, a third piece of the puzzle is the distribution and community composition of the microbes responsible for the rate transformations. At the in situ temperatures and substrate concentrations of the OMZ waters, the generation times of the microbial assemblage are on the order of a few days for denitrifiers (Ward et al. 2008) and likely a few weeks for anammox bacteria (van der Star et al. 2008). The response times of the biomass are thus longer than the response times of the processes themselves. Anammox appears to occur ubiquitously at relatively low and steady rates, while denitrification may occur slowly or rapidly in response to episodic organic matter inputs (Ward et al. 2008, Dalsgaard et al. 2012). Thus, the distribution of the microbes might represent some damped average integration over temporally varying rates of biomass production.

Earlier investigations of total microbial abundance reported microbial cell number maxima coincident with the main secondary nitrite maximum (SNM) in the OMZ (Spinrad et al. 1989, Ducklow 1993, Jayakumar et al. 2009a). Quantitative PCR-based abundances of denitrifying and anammox bacteria yield widely varying estimates of their contributions to the total microbial abundance (Hamersley et al. 2007, Galan et al. 2009, Jayakumar et al. 2009a, Lam et al. 2009, Ward et al. 2009, Casciotti et al. 2011). We investigated the distribution of the microbes responsible for the $\mathrm{N}$ loss rates using a suite of mostly functional genes related to the $\mathrm{N}$ transformations. Quantitative PCR was used to estimate the distribution of denitrifiers and anammox bacterial cells based on single copy genes, and the community composition of denitrifiers was investigated using a functional gene microarray based on nirS, the gene encoding the iron-type nitrite reductase. We expected that depth distributions of the functional genes would be consistent with the chemical distributions that define the OMZ and therefore would be similar between geographical regions. We hypothesized, however, that the community composition of denitrifiers would differ between oxic and anoxic depths and between geographical regions.

\section{MATERIALS AND METHODS}

\section{Study area and sample collection}

The data presented here were obtained from samples collected from 12 stations in the ETSP (RV 'Knorr', October 2005) and 6 stations in the AS (Stns 1, 2 and 3, RV 'Roger Revelle', September 2007; Stns 1, 2, and 23, RV 'Sagar Kanya', September 2004). Station locations are shown in Fig. 1, and details are given in Table S1 in the Supplement at www.int-res. com/articles/suppl/a070p245_supp.pdf.

Water-column sampling and temperature/salinity profiling were carried out using a Sea-Bird Electronics CTD (conductivity-temperature-depth)rosette sampling system, Model SBE9, fitted with Niskin/Go-Flo bottles. Previous work in both regions had identified strong correlations between nitrite and oxygen concentrations (Codispoti et al. 1986, Morrison et al. 1999), so we used nitrite concentration as a proxy to select sampling depths within the OMZ. Water samples from an initial cast were quickly analyzed for nitrite content. Nutrient analyses were carried out onboard ship using a SKALAR auto analyzer or manually using spectrophotometry for rapid nitrite assays (Grasshof et al. 1983), and dissolved oxygen (DO) concentrations were taken from the CTD system, which in turn was calibrated with data determined by the titrimetric Winkler method (Carpenter 1965) on discrete water samples. 

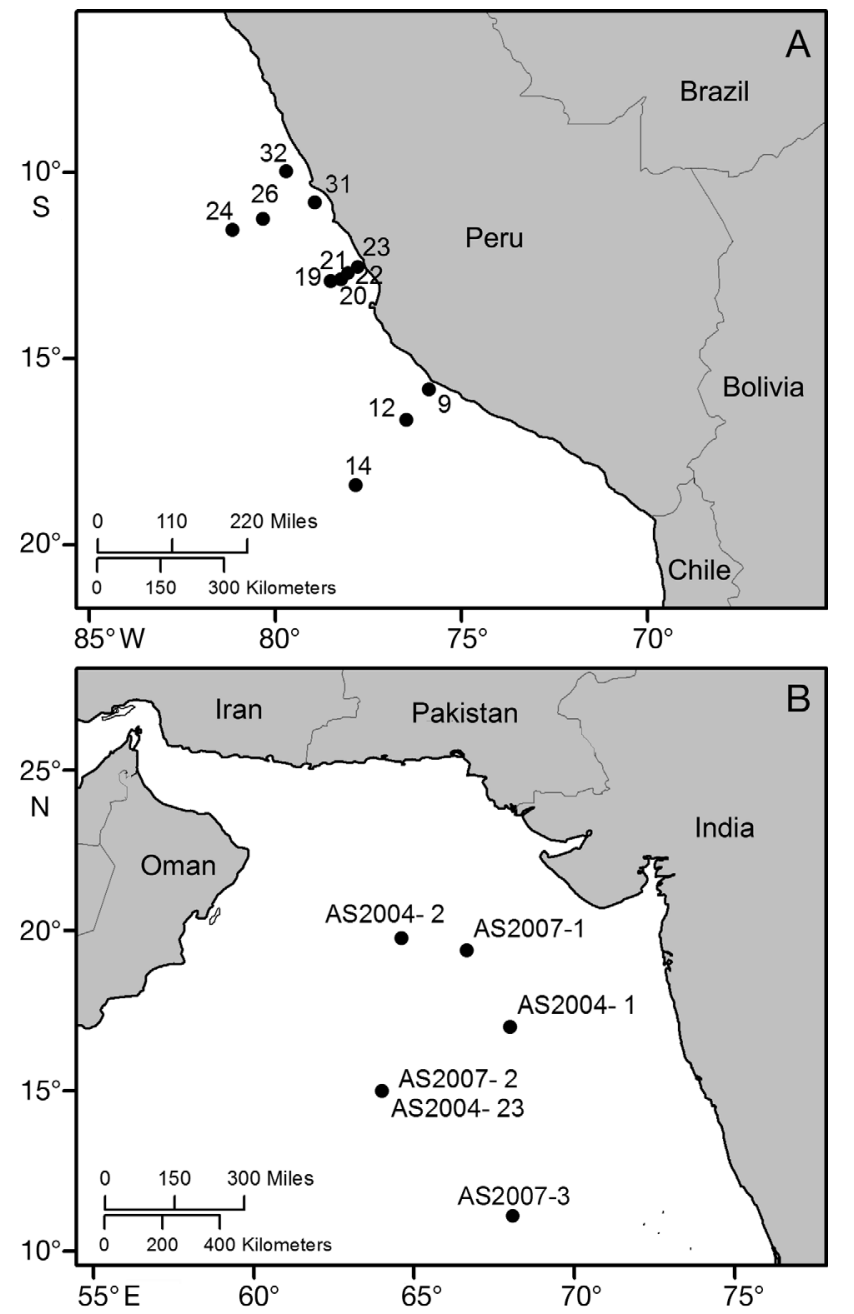

Fig. 1. Station locations for (A) Eastern Tropical South Pacific (2005) and (B) Arabian Sea $(2004,2007)$ samples

\section{Nucleic acid manipulations and quantitative PCR analysis}

Particulate material from 5 to 101 seawater was collected onto Sterivex capsules ( $0.2 \mu \mathrm{m}$ filter, Millipore) with a peristaltic pump. Immediately after filtration, the capsule filters were quick-frozen in liquid nitrogen and stored at $-80^{\circ} \mathrm{C}$ until the DNA could be extracted.

Methods of DNA extraction, PCR amplification and qPCR using SYBR Green for nirS, Dom nirs (a nirS sequence that was very abundant in clone libraries obtained previously from the AS by Jayakumar et al. 2004, 2009a) and anammox 16S rRNA genes (Schmid et al. 2003) have been described previously. Standardization and verification of specificity for qPCR assays was performed as described by Jayakumar et al. (2009b). For hzo and nirK quantification, Ex-taq Premix perfect SYBR Green Real-time master mix (Takara) was used. Primers, amplification conditions and master mix kits used for each qPCR assay are provided in Table S2 in the Supplement. After running test assays, specific kits were chosen based on amplification efficiency for a particular gene to maximize reproducibility with a single product. The efficiency of the qPCR reactions were calculated using the slopes of the standard curves: for Total nirS, Dom nirs, AMX 16S and nirK, the efficiencies ranged between 85 and $106 \%$, and for hzo, the efficiency ranged between 60 and $65 \%$. The amplified products were visualized after electrophoresis in $1.0 \%$ agarose gels stained with ethidium bromide. Standards for PCR quantification of each fragment were prepared by amplifying a constructed plasmid containing the respective gene fragment, followed by quantification and serial dilution.

Assays for each gene at all depths were carried out within a single assay plate (Smith et al. 2006). Each assay included triplicates of the no-template control (NTC), a no-primer control (NPR), $\geq 4$ standards and triplicates of known quantity of the environmental DNA samples (20 to $25 \mathrm{ng}$ ). DNA was quantified using PicoGreen fluorescence (Molecular Probes) calibrated with several dilutions of phage lambda standards, and qPCR was performed using a Stratagene MX3000P (Agilent Technologies). Automatic analysis settings were used to determine the threshold cycle $(\mathrm{Ct})$ values. The copy numbers were calculated as follows: copy number $=\left(\mathrm{ng} \times\right.$ number $\left.\mathrm{mole}^{-1}\right)$ $/\left(\mathrm{bp} \times \mathrm{ng} \mathrm{g}^{-1} \times \mathrm{g} \mathrm{mole}^{-1}\right.$ of bp) and then converted to copy number per milliliter of seawater filtered, assuming $100 \%$ extraction efficiency.

To maintain continuity and consistency among qPCR assays between the AS samples and the ETSP samples for a particular gene, a subset of samples from the previous run was included in the subsequent assay, and a new dilution series for standard curves was used in every assay. Plasmid DNA was quantified prior to every dilution series to account for DNA loss that occurs upon repeated freeze-thaw cycles.

\section{nirS microarray}

The array (BC014) was developed following the archetype array approach described and employed previously (e.g. Ward \& Bouskill 2011, Bulow et al. 2008) with 90-mer oligonucleotide probes. Each probe included a nirS-specific 70-mer region and a 
20-mer control region (5'-GTA CTA CTA GCC TAG GCT AG-3') bound to a glass slide. The design and spotting of the probes has been described previously (Bulow et al. 2008). The 164 nirS archetype probes represent $\sim 2000$ sequences from a wide range of environments, which were available in the public databases at the time the array was designed in November 2009. The probe accession numbers and sequences are listed in Table S3 in the Supplement.

\section{Target preparation, microarray hybridization and data analysis}

Array analysis was performed as described previously (Ward \& Bouskill 2011) using whole DNA extracts. Briefly, the genomic DNA was digested with HinfI and then labeled with amino-allyl-dUTP (Ambion, now Life Technologies, www.lifetechnologies. com) during linear amplification using random octamers and a Klenow polymerase (Invitrogen). The reaction contained $3.9 \mathrm{mM}$ d(AGC)TP, $0.4 \mathrm{mM}$ dTTP and $4.8 \mathrm{mM}$ dUaa and was amplified for $3 \mathrm{~h}$ at $37^{\circ} \mathrm{C}$. The Klenow product was purified by precipitation and conjugated with Cy3. The Cy3-labelled target (1000 ng) was combined with $2 \times$ hybridization buffer (1× final concentration; Agilent) and $0.25 \mathrm{pmol}$ of a Cy5-labelled complementary 20-mer standard oligonucleotide and incubated at $95^{\circ} \mathrm{C}$ for $5 \mathrm{~min}$ before being cooled to room temperature. Targets were hybridized to duplicate arrays by overnight incubation at $64^{\circ} \mathrm{C}$ and washed. The arrays were scanned with a laser scanner (Molecular Devices 4300) and analyzed with Gene Pix Pro 6.0 software (Molecular Devices). Quantification of hybridization signals was performed as described previously (Ward \& Bouskill 2011) with the following modifications. For each channel (532 nm [Cy3] and $635 \mathrm{~nm}$ [Cy5]), the average background fluorescence was recalculated after excluding background fluorescence values greater than the upper whisker of all of the background fluorescence values. The upper whisker is defined as the 75th percentile plus 1.5 times the difference between the 25th and 75th percentiles. Such a filtering process was applied within each block on a microarray to account for variability in background fluorescence between blocks within an array. Another filter was applied to remove anomalous values of $\mathrm{Cy} 3: \mathrm{Cy} 5$ ratios among the triplicate features. This filter excluded any feature with a test statistic $Z>1.9(\mathrm{CI}=$ $80 \%$ ), where $Z$ is calculated as follows:

$$
Z_{i}=\frac{r_{i}}{s / \sqrt{3}}, \quad i=1,2, \text { or } 3
$$

where $r_{i}$ represents the ratio of $\mathrm{Cy} 3$ to $\mathrm{Cy} 5$, and $s$ the standard deviation of the 3 Cy3:Cy5 ratios. The raw microarray image was checked to ensure that features filtered out actually exhibited anomalous hybridization signals. Then, a normalized fluorescence ratio (FRn) for each archetype was calculated by dividing the fluorescence signal of the archetype by the highest fluorescence signal within the same array. Then, the FRn of each archetype from the duplicate arrays were averaged. The relative fluorescence ratio (RFR) of each archetype was calculated as the contribution of FRn of the archetype to the sum of FRn of all nirS archetypes on the array and averaged for duplicate arrays from each sample. The original array data are available at Gene Expression Omnibus (www.ncbi.nlm.nih.gov/projects/geo/) at the National Center for Biotechnology Information under GEO Accession No. GSE50787 http://www.ncbi.nlm.nih. gov/geo/query/acc.cgi?acc=GSE50787.

\section{Statistical analysis}

The array data were analyzed using the vegan package in R (CRAN website; www.R-project.org) (Borcard et al. 2011). Archetypes contributing $<1 \%$ of the total signal were removed from further analysis. RFR values $>1 \%$ were transformed (arcsin[square root]) to normalize the proportional data. Environmental data were transformed (square root) and then standardized around zero (decostand in vegan). The transformed data were used in all diversity and ordination analyses according to Borcard et al. (2011). The null hypothesis that the nirS community composition did not differ between surface depths and OMZ depths or between regions was tested using multi-response permutation procedure (MRPP) (Zimmerman et al. 1985) with a significance level of $5 \%$.

\section{RESULTS}

\section{Station characteristics}

The hydrography and chemical distributions at some of these stations have been published previously (Table S1 in our Supplement; Ward et al. 2008, 2009). Stn 9 ETSP (coastal) and Stn 1 AS (AS2007-1; open ocean OMZ) provide the greatest contrast and contain the most complete qPCR profiles, so they are plotted here (Fig. 2). Data are presented in Tables S1 \& S2 for the samples analyzed in the present study. The AS stations were located 

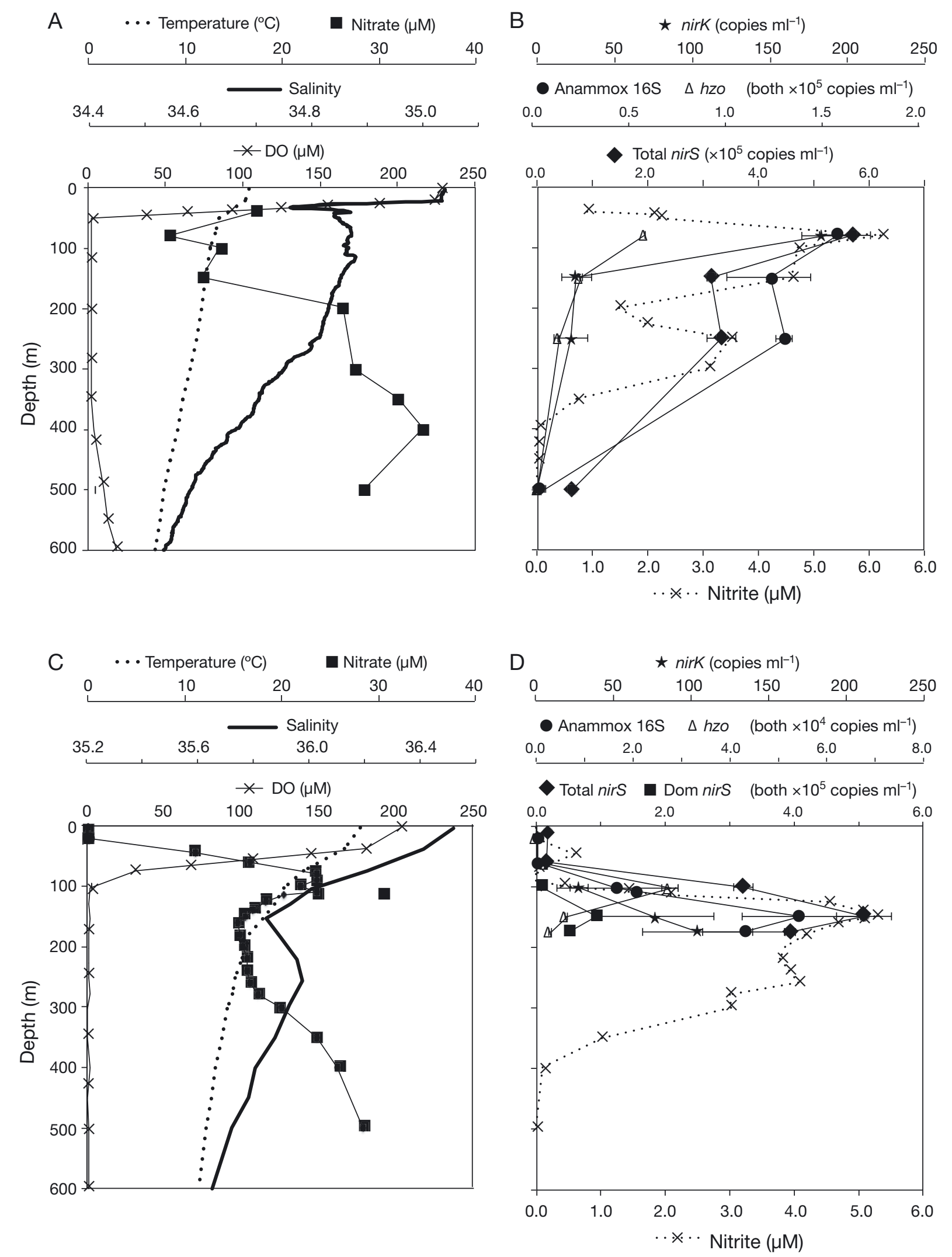

Fig. 2. (A,C) Hydrography and chemical distributions and $(B, D)$ gene abundances determined by qPCR at (A,B) Stn 9, Eastern Tropical South Pacific and (C,D) at Stn 1 in the Arabian Sea (AS2007-1) 
in the permanent OMZ (defined as waters containing at least $0.5 \mu \mathrm{M}$ nitrite) of the open ocean, while the ETSP stations included low-oxygen waters closer to the coast as well as offshore. Oxygen concentrations reported for the ODZ samples are usually in the 1 to $2 \mu \mathrm{M}$ range, but these values represent the lowest possible measurement for the CTD oxygen sensor and should not be taken at face value. The actual values are probably essentially zero, based on later measurements using the STOX sensor (Thamdrup et al. 2012).

\section{Abundances of functional genes}

Gene abundance data are presented for depth profiles of 1 station each in the ETSP and AS (Fig. 2) and for additional stations and depths in both regions (Fig. 3). Total nirS (representing the heme cd1 nitrite reductase), defined as the gene copy number from qPCR assays based on the nir1F/nir3R primers (Braker et al. 1998), was present at very low copy number in depths above the ODZ but reached values of nearly $6 \times 10^{5} \mathrm{ml}^{-1}$ in the AS and $>10^{6} \mathrm{ml}^{-1}$ in the ETSP. ETSP_31, where total nirS abundance at $20 \mathrm{~m}$ was comparable to its abundance at greater depths, might appear to be an exception to this pattern. Stn 31 is coastal and very shallow, however, and the $20 \mathrm{~m}$ depth was within the very low-oxygen water (Table S1), so the distribution of gene abundances relative to the chemical distributions is consistent with other stations.

The Dom nirS gene fragment, representing a group of sequences previously found to be a major component of clone libraries obtained from OMZ samples from a station in the central AS (Jayakumar et al. 2009a), was detected at levels up to nearly $2 \times 10^{5}$ copies $\mathrm{ml}^{-1}$ in the AS (Figs. $2 \& 3$ ) but could not be detected at all in the ETSP. Dom nirS was not detected in the surface waters but was present at all depths $>100 \mathrm{~m}$ in the AS. nirK gene fragments were always much less abundant than either form of nirS, the latter reaching maximum abundances of a few hundred gene copies per milliliter in both the ETSP and the AS.

Abundance of anammox bacteria, evaluated using both 16S rRNA genes and the functional gene hzo, were usually lower than the abundance of nirS, the putative functional gene for denitrifying bacteria. Although anammox bacteria also have a nirS gene, anammox nirS genes have not been detected in clone libraries made using these primers, so we conclude that the primers used here do not amplify the anam-
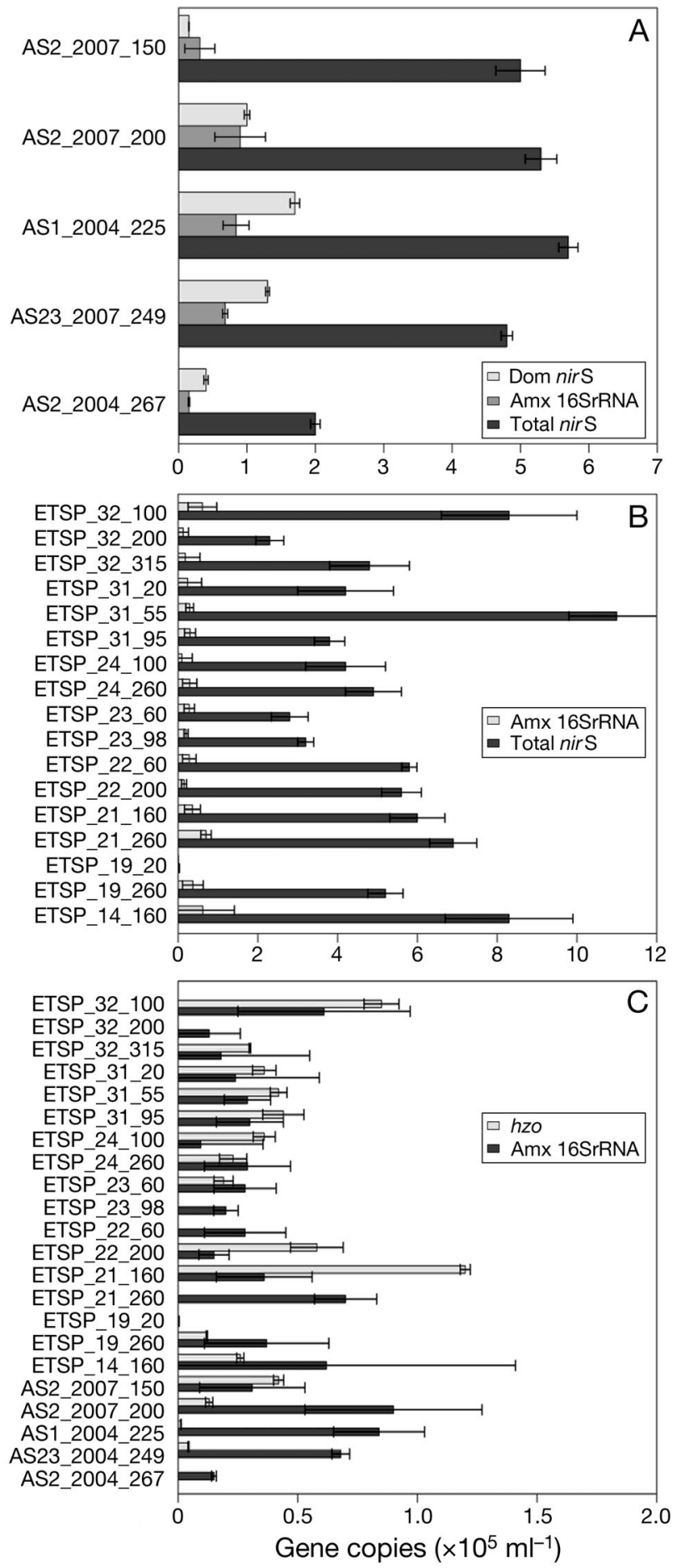

Fig. 3. Additional qPCR data. Bars represent mean and standard deviation of 3 replicate qPCR assays. The data are shown in groups or pairs for relevant comparisons. (A) Total nirS, Dom nirS and Amx 16S rRNA gene abundances at Arabian Sea (AS) stations. Sample names on the $y$-axis contain station_cruise date_depth information, e.g. AS2_2007_150. (B) Total nirS and Amx 16S rRNA at Eastern Tropical South Pacific (ETSP) stations. Sample names on the $y$-axis are site_station_depth, e.g. ETSP_32_100. (C) hzo and Amx 16S rRNA at all stations in ETSP and AS. Y-axis labels as in (B) 
mox gene. The anammox 16S rRNA gene was detected at slightly more than $2 \times 10^{5}$ copies $\mathrm{ml}^{-1}$ in the ETSP (Figs. $2 \& 3$ ) and up to $10^{5}$ copies $\mathrm{ml}^{-1}$ in the AS (Figs. 2 \& 3). The hzo gene abundance was variable, and the ratio of hzo:16S rRNA ranged from 0.01 to 2.3, with a median of 0.43 (Fig. 3).

\section{Community composition of denitrifying bacteria}

Community composition in terms of relative archetype abundance (RFR) is presented for surface and OMZ depths for several stations in the ETSP and for surface, oxycline and OMZ depths in the AS. The Shannon-Wiener diversity index $\left(H^{\prime}\right)$ and ShannonWiener evenness index $(E)$ computed from the RFR microarray data ranged from 3.0 to 3.5 and from 0.961 to 0.995 , respectively, and neither measure varied significantly between regions (ETSP vs. AS) or between depths (surface vs. OMZ) (Table 1, Table S4 in the Supplement).

Table 1. Diversity measures for array samples. 'Richness': number of archetypes present at $>1 \%$ of total nirS signal; \% RFR: total fraction of nirS hybridization signal represented by archetypes present at $>1 \%$ of the total signal; $H^{\prime}$ : Shannon-Wiener diversity index, calculated in $\mathrm{R}$ (vegan); $E$ : Shannon-Wiener evenness index, calculated in R (vegan). Station codes as in Fig. 3

\begin{tabular}{|llcccc|}
\hline $\begin{array}{l}\text { Sample } \\
\text { No. }\end{array}$ & Station & 'Richness' & $\begin{array}{c}\text { RFR } \\
\%\end{array}$ & $H^{\prime}$ & $E$ \\
\hline 1 & & & & \\
2 & ETSP_12_20 & 28 & 45.2 & 3.316 & 0.984 \\
3 & ETSP_12_260 & 32 & 48.8 & 3.452 & 0.986 \\
4 & ETSP_14_20 & 26 & 49.0 & 3.230 & 0.973 \\
5 & ETSP_14_260 & 35 & 74.4 & 3.519 & 0.964 \\
6 & ETSP_19_20 & 26 & 49.3 & 3.229 & 0.972 \\
7 & ETSP_19_260 & 28 & 45.6 & 3.309 & 0.977 \\
8 & ETSP_20_20 & 22 & 31.8 & 3.078 & 0.987 \\
9 & ETSP_20_260 & 25 & 44.2 & 3.201 & 0.982 \\
10 & ETSP_24_20 & 29 & 50.9 & 3.328 & 0.961 \\
11 & ETSP_24_260 & 21 & 44.0 & 3.020 & 0.976 \\
12 & ETSP_26_20 & 30 & 47.2 & 3.386 & 0.985 \\
13 & ETSP_26_260 & 28 & 44.4 & 3.314 & 0.982 \\
14 & ETSP_31_55 & 35 & 70.0 & 3.531 & 0.976 \\
15 & ETSP_32_260 & 26 & 38.7 & 3.252 & 0.994 \\
16 & AS_1_10 & 30 & 48.7 & 3.388 & 0.986 \\
17 & AS_1_60 & 25 & 35.7 & 3.210 & 0.992 \\
18 & AS_1_102 & 27 & 45.2 & 3.272 & 0.976 \\
19 & AS_1_150 & 30 & 49.1 & 3.380 & 0.979 \\
20 & AS_1_175 & 28 & 41.6 & 3.313 & 0.981 \\
21 & AS_2_10 & 29 & 39.9 & 3.362 & 0.995 \\
22 & AS_2_150 & 29 & 44.1 & 3.357 & 0.990 \\
23 & AS_2_200 & 29 & 48.7 & 3.347 & 0.979 \\
24 & AS_3_10 & 29 & 45.9 & 3.353 & 0.986 \\
25 & AS_3_110 & 28 & 42.8 & 3.324 & 0.992 \\
& AS_3_150 & 30 & 47.4 & 3.391 & 0.990 \\
\hline
\end{tabular}

Because the microarray was limited to 164 archetypes, it is not strictly speaking possible to compute a measure of richness from the array data. Rather, we report 'Richness' as the number of archetype probes that contributed $>1 \%$ of the total nirS RFR at each station. This value of 'Richness' ranged from 21 to 35 , and the signal contributed by these probes (\%RFR) ranged from 32 to $74 \%$ of the total nirS signal on the array. The highest \%RFR values, $70 \%$ and $74 \%$ for ETSP_31_55 and ETSP_14_260 respectively, were both from OMZ samples. However, \%RFR did not differ significantly between OMZ and surface samples within or across regions (Tables $1 \&$ S4).

Initial inspection of the array data (RFR for each archetype, i.e. the percent of the total nirS hybridization signal contributed by an individual archetype) yields a few overall patterns. Of the 164 archetypes probes represented on the array, 76 of them were never detected at RFR $>1 \%$ in any sample from either region. No archetypes were present (i.e. contributed $>1 \%$ of the total nirS signal) in all samples at all stations, but several (N4, N54, N56, N141, N44, N93 and N111) were detected in 22 or 23 of the total 25 samples (Table S5 in the Supplement). Five archetypes (N4, N54, N56, N111 and N141) were present in all of the AS samples, and 1 (N44) was present in all but 1 AS sample. Only 1 archetype, N133, was present in all ETSP samples, and it was also detected in 5 of the 11 AS samples. Thus, no truly ubiquitous archetypes were evident, but it was likewise rare to find complete separation between regions or depths in archetype occurrence: 13 archetypes occurred only in the AS, and a different set of 13 archetypes occurred only in the ETSP.

A few archetypes were detected more frequently in either the shallow or OMZ samples; for example, N84, N88 and N89 (all representing estuarine sediment sequences) were all present in many of the OMZ samples, and of these, only N89 was detected in 1 surface sample. N130 was present in all OMZ samples from the AS, 6 of the 8 ETSP OMZ samples, and no surface samples from either region. N151 was detected only in OMZ samples, mainly from the AS. N90 was detected in surface samples from both regions but in only 1 OMZ sample (ETSP).

Overall patterns of community composition on the basis of archetype RFR signals were explored quantitatively using dissimilarity analysis. A heatmap of Bray-Curtis dissimilarity values for all stations shows that the 2 regions cluster somewhat separately in terms of assemblage composition (Fig. S1 in the Supplement). So although the basic diversity measures were not significantly different (Table S4) 


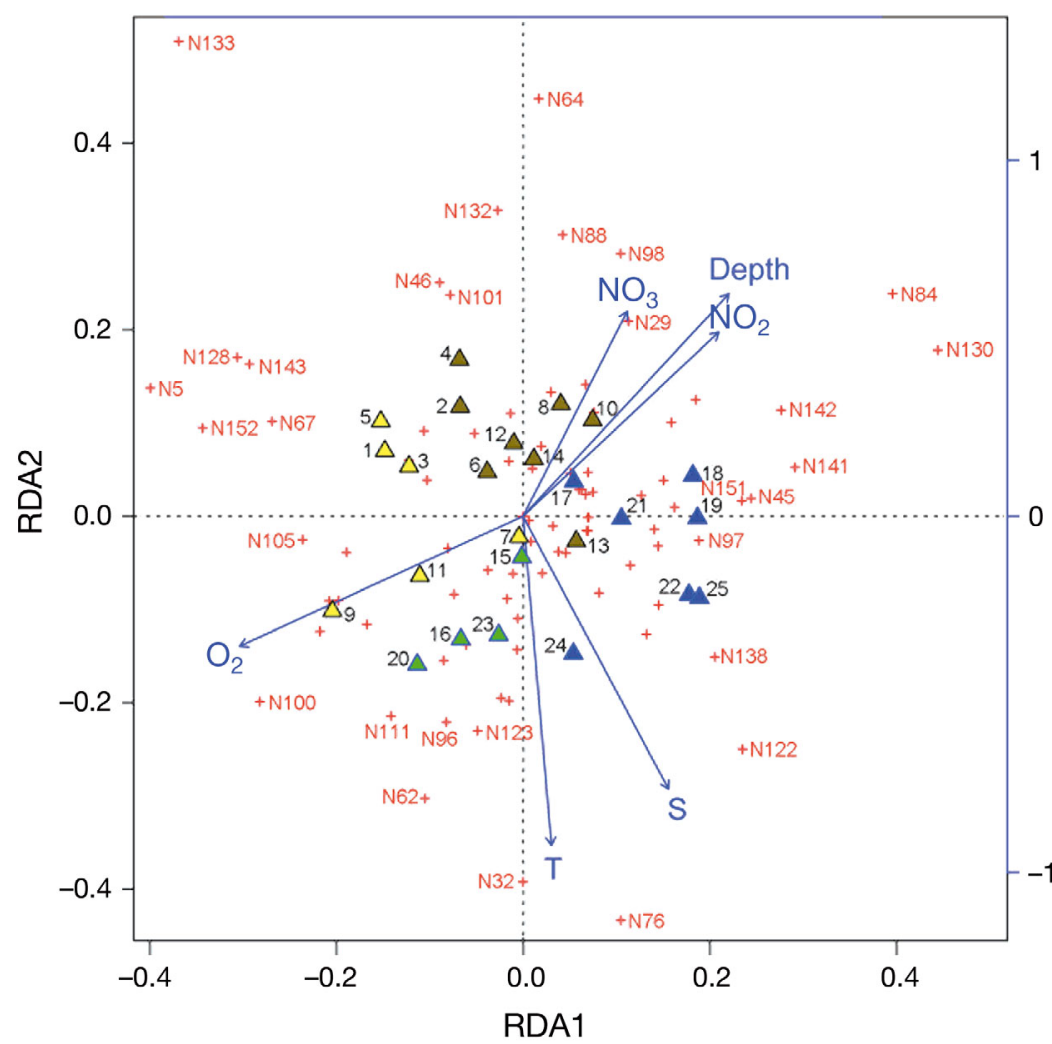

Fig. 4. Triplot of redundancy analysis (RDA) based on a correlation matrix combining physicochemical and biological (FRn) factors for the combined Eastern Tropical South Pacific (ETSP) and Arabian Sea (AS) datasets. Archetypes are represented by probe names (N1, N2, etc.). Physicochemical variables: S: salinity; T: temperature; $\mathrm{NO}_{2}$ : nitrite concentration; $\mathrm{NO}_{3}$ : nitrate concentration; Depth; $\mathrm{O}_{2}$ : oxygen concentration. Yellow triangles: surface ETSP samples; brown triangles: OMZ ETSP samples; green triangles: AS surface samples; blue triangles: OMZ AS samples (numbers identifying samples are listed in Table S1 in the Supplement). The scale on the left vertical axis is for coordinates of samples and archetypes; the scale on the right vertical axis is for coordinates of environmental variables

between regions, the actual archetypes contributing to the diversity measures did differ between regions.

Environmental variables were added to the community analysis using redundancy analysis (RDA). The normalized RFR values for each sample and a set of 6 environmental variables for each sample were combined for RDA, resulting in the triplot for the combined ETSP and AS data shown in Fig. 4. The most obvious environmental trend is the negative correlation of $\mathrm{O}_{2}$ vs. $\mathrm{NO}_{2}, \mathrm{NO}_{3}$ and depth in opposite quadrants of the plot. Both RDA 1 (11.2\% of the variance) and RDA 2 (6.8\% of the variance) contribute to a 'depth axis', which runs diagonal across Quadrants 1 and 3. Temperature is part of the 'depth axis', positively correlated with $\mathrm{O}_{2}$, while salinity is nearly orthogonal to the 'depth axis'. Temperature and salinity clearly differentiate the conditions of the surface and OMZ samples. Pairwise correlation analysis (Pearson's r) showed that among the environmental variables, only temperature and salinity were correlated with $r>0.7$, so all the environmental variables were retained in the RDA analysis.

The ETSP and AS stations form nearly separate clusters in the triplot (Fig. 4), with some overlap (2 ETSP samples, numbered 7 [ETSP_20_20] and 13 [ETSP_31_55]). This regional separation suggests that the community composition is at least partly due to the environmental conditions at the original sample depths. Not only are the ETSP and AS separated in the triplot, but within each region, the surface and OMZ depth samples are also clearly separated. The shallow samples cluster positively with $\mathrm{O}_{2}$, while the OMZ samples for both regions correlate positively with $\mathrm{NO}_{2}$, $\mathrm{NO}_{3}$ and depth. The RDA components 1 to 6 cumulatively account for only $33 \%$ of the variance, indicating that $67 \%$ of the variance is unconstrained by the measured variables.

When data from the 2 regions were analyzed separately by RDA in order to further investigate the clustering of surface and deep (OMZ) samples within regions, the same environmental distinctions were clear (Figs. S1 \& S2 in the Supplement). Although the 6 environmental variables contribute differentially to the first 2 RDA axes in the 2 regions, the 6 variables cluster into 2 groups to define a depth axis that bisects the 2 main RDA axes, as in the combined analysis. RDA again separated the surface and OMZ samples within each region (Figs. S1 \& S2), although considerable scatter is evident, particularly among the OMZ samples in the ETSP. The first 2 RDA components account for $28 \%$ and $35 \%$ of the variance for the ETSP and AS, respectively.

For all 3 analyses (ETSP and AS combined, and ETSP and AS separately), the 6 RDA components explained only a small portion of the total variance in the data. Nevertheless, the adjusted $\mathrm{R}^{2}$ values were significant for the combined dataset and for the ETSP alone (Table 2). 
Table 2. Results of redundancy analysis (RDA). AS: Arabian Sea samples; ETSP: Eastern Tropical South Pacific samples

\begin{tabular}{|c|c|c|c|c|c|c|c|c|c|c|c|c|}
\hline & \multirow[b]{2}{*}{ RDA 1} & \multirow[b]{2}{*}{ RDA 2} & \multirow[b]{2}{*}{$\begin{array}{l}\text { RDA } 1+ \\
\text { RDA } 2\end{array}$} & \multicolumn{4}{|c|}{ - Proportion of variance explained by RDA } & \multirow[b]{2}{*}{$\begin{array}{c}\text { Total } \\
\text { unconstrained }\end{array}$} & \multirow[b]{2}{*}{$\begin{array}{c}\text { Total } \\
\text { explained }\end{array}$} & \multirow{2}{*}{$\overline{\text { Total }}$} & \multirow{2}{*}{$\begin{array}{c}\text { p-value } \\
\text { RDA1 }\end{array}$} & \multirow{2}{*}{ RDA2 } \\
\hline & & & & $\mathrm{R}^{2}$ & Adj. $\mathrm{R}^{2}$ & $\begin{array}{c}\text { Adj. } R^{2} \times \\
(\text { RDA } 1+ \\
\text { RDA 2) }\end{array}$ & $\begin{array}{c}\text { Total constrained } \\
\text { (Sum of RDA1 } \\
\text { to RDA6) }\end{array}$ & & & & & \\
\hline $\begin{array}{l}\text { Combined } \\
\text { ETSP + AS }\end{array}$ & 0.112 & 0.068 & 0.180 & 0.327 & 0.102 & 0.02 & 0.33 & 0.67 & 0.034 & 0.006 & 0.001 & 0.022 \\
\hline ETSP & 0.164 & 0.119 & 0.283 & 0.547 & 0.160 & 0.05 & 0.55 & 0.45 & 0.088 & 0.037 & 0.041 & 0.074 \\
\hline AS & 0.228 & 0.123 & 0.351 & 0.614 & 0.035 & 0.01 & 0.61 & 0.39 & 0.021 & 0.400 & 0.069 & 0.335 \\
\hline
\end{tabular}

Each individual archetype is also plotted on the RDA triplots; only those with the longest vectors from the origin (highest correlations) are labeled in the plots. Projecting a sample at right angle on an archetype vector (red) approximates the value of the sample along that archetype. The angles between the archetype vectors (red) and explanatory variable vectors (blue) reflect their correlations (a small angle close to zero suggests a high positive correlation; a large angle close to $180^{\circ}$ suggests a high negative correlation; a right angle suggests no correlation). The angle between a response variable (the archetype value) and the environmental variable reflects the correlation between them, and the angle between vectors connecting archetype points to the origin indicates correlations between archetypes. It is therefore interesting to consider individual archetypes that display consistent behavior between stations and to compare these results to those observed in the patterns detected from preliminary observation of the data above. For example, N130 had a high value for RDA 1 in both regions and was very strongly correlated with $\mathrm{NO}_{2}$, depth and $\mathrm{NO}_{3}$. N130, in the first quadrant showing high positive correlation with the 'depth axis', was present in all 7 of the OMZ samples from the AS, in 5 of the $8 \mathrm{OMZ}$ samples from the ETSP, and was never detected in surface samples from either region. Similarly, N84, close to N130 in the plot, occurred in most of the OMZ samples from both regions and was never detected in the surface.

In the ETSP, N141, N56 and N46 occurred primarily in deep/OMZ samples, while N111 was present in all the surface samples and absent in several of the deep samples. In the AS, N130, N142, N151 and N45 were all predominantly associated with deep/OMZ samples, while N152 and N128 had the opposite distribution. N98 and N63 were evenly distributed between deep and surface samples with nearly opposite patterns of occurrence among individual stations (i.e. these 2 archetypes lie in opposite quadrants of the plot, and their vectors are perpendicular to the 'depth axis' defined by the 6 environmental variables).

The significance of community composition differences between regions and depth intervals was tested using MRPP. The 2 regions, ETSP and AS, were significantly different overall ( $p=0.004)$, as were the surface and deep communities combined across regions $(p=0.011)$. The surface and deep samples within the AS were significantly different $(\mathrm{p}=$ 0.018), while the surface and deep assemblages in the ETSP were not significantly different at the $5 \%$ level $(p=0.146)$.

\section{DISCUSSION}

\section{Abundances of genes associated with bacteria involved in $\mathbf{N}$ cycling in the $\mathrm{OMZ}$}

The 2 stations for which qPCR data on several functional genes related to anoxic $\mathrm{N}$ cycling are shown represent 2 different geographic regions as well as 2 different oceanic regimes. ETSP Stn 9 is in $<1000 \mathrm{~m}$ of water and located very close to the coast, within the coastal upwelling zone, while AS Stn 1 (AS20071) is in the open ocean OMZ of the AS, far away from the coastal influence. The depth distributions of the functional genes relative to chemical distributions are similar at both stations. In the AS, both nitrite and functional genes showed maxima in the ODZ, while at Stn 9 in the ETSP, all gene abundances essentially decreased with depth because we did not sample above the ODZ at this station.

The distribution of nirS, nirK, anammox 16S rRNA and hzo genes were all consistent with the environmental conditions that define the OMZs in both regions; i.e. although the absolute abundances of the genes differed, they all exhibited maxima in the depth interval defined by nitrite concentration as the core of the ODZ. In the AS, maxima in all the functional 
genes and the anammox 16S rRNA gene coincided with the SNM. Although total cell count data are not available for this station at the time of sampling, we expect that the maximum in total microbial cells also occurred at the depth of the nitrite maximum, as has been reported for this station in the past (Jayakumar et al. 2009b) and other regions in the AS OMZ (Ducklow 1993). Total cell abundance maxima also coincided with the SNM in historical data from the ETSP (Spinrad et al. 1989). It has been argued recently that the SNM is a relict feature, indicative of previous intense N-transformation activity when the water mass was located elsewhere, presumably in a very active coastal zone (Varela et al. 2011) Advection as a cause of a maximum in cell number or chemical concentration seems unlikely because diffusion would destroy the maximum, and its maintenance would require counteractive accumulating processes. The higher concentration of cells implied by the functional gene abundances implies an active maintenance of the populations associated with these chemical features, even in the absence of simultaneous data on gene expression or nitrogen transformation rates.

The failure to detect nirS by qPCR in surface waters, and the failure to obtain nirS sequences by PCR in clone libraries in surface waters in the past, show that nirS genes, and by inference, denitrifying bacteria, are rare in surface waters. Although most known denitrifying bacteria are facultative aerobes, they are apparently not competitive with the strict aerobes that dominate surface waters. Abundances based on qPCR of OMZ samples, however, suggest the denitrifiers comprise $\geq 10 \%$ of the microbial assemblage in the OMZ (Figs. 2 \& 3). If the total assemblage, as enumerated by acridine orange or DAPI, reaches a maximum of $2 \times 10^{6}$ cells ml$^{-1}$ in the core of the OMZ in the ETSP (Spinrad et al. 1989), the total nirS abundance maximum of $10^{6} \mathrm{ml}^{-1}$ represents $50 \%$ of the assemblage. Even if only a few phylotypes are truly abundant at any one time, this total abundance of nirS denitrifiers implies that possession of the nirS gene, and the implied ability for denitrification, is selective in the OMZ environment. We have argued in the past that the vast diversity of nirS genes in the OMZ acts as a reservoir from which different strains bloom in response to episodic organic matter supply (Ward et al. 2008, Jayakumar et al. 2009b).

Although the total depth of ETSP Stn 9 is nearly $1000 \mathrm{~m}$, the steepness of the shelf in this region puts that station within $23.5 \mathrm{~km}$ of the coast. Two nitrite maxima were present, one very shallow, but both in very low oxygen waters. The functional genes associ- ated with anoxic $\mathrm{N}$ cycling, nirS, nirK and hzo, as well as the anammox 16S rRNA gene all had abundance maxima at the depth of the upper nitrite maximum, and their abundance declined in deeper waters. Both nirS and Amx 16S rRNA genes had an indication of a slight secondary maximum at the depth of the deeper nitrite maximum. The depth patterns of these genes are consistent with the abundance of microbes involved in these processes being correlated with and controlled by the physical/chemical processes that define the OMZ. This station is somewhat similar in habitat characteristics to the most offshore station (Stn 7, $93 \mathrm{~km}$ from the coast in $2400 \mathrm{~m}$ ) described by Hamersley et al. (2007), who detected a very similar number of copies of anammox 16S rRNA genes, $\sim 6 \times 10^{4} \mathrm{ml}^{-1}$, compared to the maximum of $10^{5} \mathrm{ml}^{-1}$ reported here.

Abundances of total nirS in both the ETSP and AS were high, representing a large fraction of the expected total abundance of prokaryotic microbes in the OMZ and a much smaller fraction in the oxic surface water. The total nirS primers used here have broad specificity, amplifying a great diversity of nirS genes present in the OMZ (Jayakumar et al. 2009a). Changes in diversity of the denitrifier community associated with different stages of denitrification (Jayakumar et al. 2009b) imply that the community composition of the active denitrifiers varies transiently, so use of more selective primers might miss a variable portion of the assemblage. The Dom nirS clade illustrates this issue. The Dom nirS primers were developed specifically to amplify one clade of nirS genes that were very abundant in clone libraries from OMZ waters at Stn 1 in the AS in 2004 (AS20041; Jayakumar et al. 2009a). The Dom nirS primers detected this gene fragment at levels of 20 to $30 \%$ of total nirS in 2004. In the 2007 samples described here, the Dom nirS fragment abundance estimated by qPCR was equivalent to 2 or $3 \%$ (in the oxycline depths at the top of the OMZ) up to $30 \%$ (in the SNM) of the total nirS gene abundance. Although total nirS abundance was similar in the AS and the ETSP OMZ samples, Dom nirS could not be detected at all in the ETSP samples. This distribution suggests that organisms with the Dom nirS sequence are important members of the AS nirS assemblage at depths where rate measurements (Ward et al. 2009, Bulow et al. 2010) indicated that denitrification was occurring, but these organisms are not important in the ETSP. We interpret this to suggest that different nirS clades are abundant, and probably active, at different times and places against a background of vast overall denitrifier diversity. 
This explanation is also consistent with the observations of Lam et al. (2009) and Hamersley et al. (2007); these 2 papers presented the same results for a study off the coast of Peru just north of the region of our Stn 9. The total nirS primers used in that study were selected because they amplified a fragment that had been found previously to be highly expressed in OMZ samples (Lam et al. 2009). In the ETSP, the total nirS DNA and RNA gene copy abundances estimated by qPCR with these primers was on the order of a few hundred (up to 200) copies per milliliter. These primers were designed and used in the past for amplification of nirS genes from estuarine sediments (Throbäck et al. 2004). It seems likely that the clade targeted by them was a minor component of the total denitrifier assemblage at the time of that study and in the later study by Kalvelage et al. (2013). In fact, most nirS clades are probably minor components of the assemblage most of the time, but a few of them bloom under certain conditions. By this reasoning, we might expect that Dom nirS is not a permanent feature of the denitrifying assemblage of the AS, and that some other clade might bloom at a different time (Jayakumar et al. 2009b). Thus, the more general total nirS primers allow quantification of the background diversity, while the dynamics of individual clades might be traceable with more specific primers or probes but will most likely be missed due to the random nature of the bloom process.

The copper-type nitrite reductase enzyme, encoded by nirK, has a wider phylogenetic distribution than the cd heme enzyme, encoded by nirS (Zumft 1997), and the genes encoding it are more variable. Several different sets of nirK primers have been tested in different environments, and the abundances are generally lower than nirS in the same environments. The present results are consistent with those observations, but it is still likely that the nirK primers used here were not capable of amplifying the total diversity of nirK genes present. Thus, these data are a minimal estimate of the abundance of nirK denitrifiers, but the subset detected have a distribution in parallel with the nirS type denitrifiers detected with the total nirS primers. These nirK primers do amplify nirK genes related to bacterial ammonia oxidizers (Santoro et al. 2006), but the abundances of nirK detected here are much lower than reported abundances of $\mathrm{AOB}$ in the AS and ETSP (Lam et al. 2009, Newell et al. 2011, Bouskill et al. 2012).

In contrast to denitrifying bacteria, anammox bacteria have usually been identified and quantified using the 16S rRNA gene. Despite using PCR primers intended to amplify 16S rRNA genes from all known genera of anammox bacteria (Schmid et al. 2003), only the genus Scalindua has been reported from ODZ depths (Schmid et al. 2007, Stevens \& Ulloa 2008, Woebken et al. 2008, Galan et al. 2009, Jayakumar et al. 2009a). Anammox 16S rRNA clone libraries from all of these studies portray a very low-diversity assemblage of anammox bacteria in the OMZ, perhaps only 1 or 2 operational taxonomic units (OTU) at a divergence of $98 \%$ identity among sequences.

The abundance of anammox 16S rRNA genes at the 2 stations reported here are on the same order as reported previously for these regions (Hamersley et al. 2007, Ward et al. 2009). Hamersley et al. (2007) reported anammox 16S rRNA gene abundance of up to $6 \times 10^{4}$ copies $\mathrm{ml}^{-1}$ at their offshore station and up to $1.5 \times 10^{5}$ copies $\mathrm{ml}^{-1}$ at the most onshore station. Lam et al. (2009) reported copy numbers for the nirS gene specific to the anammox genus Scalindua from the same samples, allowing us to calculate an average ratio of nirS:16S rRNA genes of $\sim 0.05$. (When both genes were detected by Lam et al. (2009), nirS was much less abundant than 16S rRNA; however, in 3 cases, a few hundred nirS gene copies were reported while anammox 16S rRNA gene abundance was essentially zero.) Both of these genes, as well as the hzo gene, are reported to occur as single copies in the Scalindua genome (van de Vossenberg et al. 2013). In silico analysis of the primers used here tested against the GenBank database indicates that the hzo primers should not amplify any of the related hao genes in Scalindua or other genera. That makes it hard to explain why the anammox 16S rRNA genes are so much more abundant than both of the functional genes. It is possible that there is much more microdiversity at the functional gene level, and because the primers used here for hzo and by Lam et al. (2009) for nirS are based on a single genome, they are unable to detect even closely related sequences. Lower qPCR amplification efficiency for hzo relative to the other genes also contributes to the lower abundances, but this is not the case for nirK. Thus, the hzo abundances may not be interpretable in terms of anammox cell abundance, even though their relative distribution is consistent with our expectation of the distribution of the cells. Abundances of hzo reported here are similar to the ranges reported from the ETSP by others (e.g. Galan et al. 2009, Kalvelage et al. 2013). A large number of genes with identity to Keunenia stuttgartiensis, but probably associated with Scalindua, were highly expressed in coastal low-oxygen waters of the ETSP (Stewart et al. 2012). 


\section{Community composition of denitrifying assemblages}

The previously published diversity studies, based on clone libraries, and the quantitative distributions shown here indicate differences in the community composition of denitrifying bacteria between regions and among depths within regions. The functional gene microarray used here allowed for greater throughput and replication for further investigation of community composition. The array experiments focused on detecting the greatest contrasts, i.e. comparing surface and OMZ samples within and between the ETSP and the AS, rather than analyzing comprehensive depth profiles.

The utility of the microarray depends on the scope of the sequence database it represents and the resolution afforded by the probe selection. The probe set was developed in 2009 when there were several thousand nirS sequences in the public databases. The 70-mer probe region was chosen to include the greatest sequence variability within the $\sim 900 \mathrm{bp}$ fragment defined by the nirS PCR primers $1 \mathrm{~F}$ and $6 \mathrm{R}$ (Braker et al. 1998). Therefore, the phylogeny reflected in the 70-mer probe sequences is not entirely coherent with that derived from the longer $900 \mathrm{bp}$ sequences. The 164 probes represent the database sequences using an archetype approach; i.e. the probe selection algorithm chooses sequences that represent all sequences within $15 \%$ distance of the archetype sequence, using an iterative procedure that minimizes the number of archetypes and the number of overlaps (sequences that would hybridize with $>1$ probe) (Bulow et al. 2008). Most of the archetypes tend to represent groups of sequences from single environments; e.g. N1 represents a few hundred nirs sequences from estuarine sediments and shallow coastal water, N2 represents sequences from the oxygen minimum zone of the AS, and N4 represents sequences from the OMZ of the ETSP. It cannot be assumed, however, that there is no overlap between geographical or environmental boundaries. For example, some of the archetypes that were detected predominantly in OMZ samples (N84, N88 and N89) were derived from sequences obtained previously from estuarine sediments, while N130, which was detected in every OMZ sample, was derived from a single sequence collected from coastal sediments. These probe affiliations likely reflect the preponderance of estuarine and coastal sediment sequences in the database at the time of the array design. It is clear that some of those sediment sequences are also common in nirS genes from organisms living in low- oxygen seawater. At the time the array was designed, only 1 nirs sequence from anammox bacteria was available, that being from Kuenenia stuttgartiensis. The $K$. stuttgartiensis nirS sequence was included on the array as archetype probe N99 and was never detected at $>1 \%$ of the total nirS signal. The recently available nirS sequence from Candidatus Scalindua profunda is only $57 \%$ identical with the Kuenenia sequence and is at least as distant from all known heterotrophic denitrifier nirS sequences. Thus, Scalindua nirS sequences could not be detected by any probes represented on the array, although they were likely quite abundant in the samples.

Although the archetypes are not uniquely associated with particular types of environment, the assemblages (i.e. the combinations of different archetypes and their relative abundances) detected by the array are distinct between regions. The most striking result from the array data is the near complete separation of communities in the AS vs. the ETSP, even though there were very few individual archetypes that were completely absent or always present in one region or the other. Similar biogeographical patterns were observed in recent analyses of thousands of amoA sequences from ammonia-oxidizing archaea (Biller et al. 2012, Pester et al. 2012): biogeography was more highly correlated than were environmental characteristics with community composition of ammonia-oxidizing archaea. Based on the generality of biogeographical distributions, we conclude that the difference in community composition observed between the ETSP and AS was due to geographical separation rather than to the coastal vs. oceanic natures of the 2 regions.

Extrapolating from published clone library data using richness estimators implies that hundreds, if not thousands, of nirS OTUs may be present in estuarine environments, and fewer, but still more than were represented on the array, in open ocean environments (Jayakumar et al. 2009a, Francis et al. 2013). Thus, the number and coverage of the probes contained on the microarray used here no doubt miss much of the possible diversity of nirS that might be present in the environment. However, because the probe set was developed from sequences that were obtained from clone libraries, it is possible that some of the most abundant (within the uncertainty of cloning and PCR bias) OTUs from estuarine and open ocean environments were in fact included on the array. An earlier version of the array, containing only 40 archetype probes, detected the strongest signals, in both DNA and RNA, from probes representing the most common sequences in 
clone libraries from the same stations in Chesapeake Bay (Bulow et al. 2008). So, although the array cannot be used to explore the limits of diversity in a new environment or to identify new sequences, it has the clear advantage of being able to compare community composition, on the basis of the existing sequence database, for large numbers of samples with replication without building large numbers of clone libraries. In the present study, the arrays were hybridized to targets prepared from whole DNA samples, thus avoiding PCR bias at this step.

Although undetectable by PCR, nirS archetypes were detected in surface waters by hybridization with the microarray. These low-abundance denitrifiers comprised a different community, however, from that found at higher abundances in the OMZ. The evenness estimated for the nirS communities of the OMZ did not suggest the presence of blooms at the time of sampling. If a bloom had occurred by a previously rare phylotype, not represented in the database on the array, we would not have detected it. Clone libraries were not analyzed for the simultaneous comparison.

Several of the archetypes were based on sequences solely or predominantly derived from OMZ environments in the ETSP or AS. Only one of these, N4, was detected frequently in multiple samples in the array data. N4 is not labeled on the triplots because it does not have a long vector; i.e. it occurred in all but 2 samples and was not correlated differentially with any of the environmental variables. Other nearly ubiquitous archetypes included N44, N45 and N46, all represented by sequences obtained from low-oxygen coastal waters in the AS. Only N45 is labeled on the triplot in Fig. 4, and its occurrence was most noticeably negatively correlated with oxygen and not particularly strongly positively correlated with any other variables. N46 was strongly positively correlated with $\mathrm{NO}_{3}, \mathrm{NO}_{2}$ and depth, clearly associated with OMZ samples in the ETSP but not in the AS (Figs. S1 \& S2).

Based on the qPCR data and previous clone library work, we expected to detect the sequence amplified by the Dom nirs primers as a major component of the nirS array signal. Dom nirS sequences were represented by archetype probe N3, which was never detected at $>1 \%$ of the total nirS signal. We have no satisfactory explanation for this lack of consistency. In previous comparisons between microarray and clone library representation or qPCR abundance, the microarray targets were prepared by labeling PCR products; i.e. the targets were prepared from the same PCR fragments that had been used to obtain most of the sequence data in the database. In the present comparison, the array targets were prepared from whole DNA, without PCR amplification. This approach should reduce primer bias, but it also results in a lower overall signal because most of the labeled target DNA does not bind to probes on the array. This difference therefore might imply that primer bias accounts for the abundance of the dominant nirS sequence in the previously described clone libraries. However, quantitative PCR also detected the Dom nirS sequences at high abundance in the OMZ samples in the AS. It is possible that the qPCR primers amplify sequences that match at the primer site but do not hybridize well in the 70-mer region represented by the probe on the array.

\section{CONCLUSIONS}

The quantitative distributions of the functional genes associated with key processes in the $\mathrm{N}$ cycle are correlated with the chemical characteristics of the OMZ in both the ETSP and the AS. As represented by their signature genes, denitrifiers that use the nirS gene by far outnumber those with the nirK gene, and the total number of denitrifiers represents a major component of the total microbial population at OMZ depths. Anammox bacteria are somewhat less abundant, and the discrepancy between gene copy numbers of the 16S rRNA gene and 2 functional genes from Scalindua, hzo and nirS, all thought to be present in 1 copy each in the anammox genome, suggests microdiversity within the functional genes, while 16S rRNA gene sequence analysis has previously detected only the Scalindua genus.

The main pattern detected in the nirS denitrifier community composition is regional separation between communities of the ETSP and AS, even though few individual archetypes were specific to particular sites or depths. Unlike PCR and qPCR, the arrays did detect some denitrifier archetypes in surface waters, but the assemblages in surface waters and waters at the depth of the OMZ were distinct.

\section{LITERATURE CITED}

Bange HW (2008) Gaseous nitrogen compounds (NO, $\mathrm{N}_{2} \mathrm{O}$, $\mathrm{N}_{2}, \mathrm{NH}_{3}$ ) in the ocean. In: Capone DG, Bronk DA, Mulholland MR, Carpenter EJ (eds) Nitrogen in the marine environment. Elsevier, Amsterdam, p 51-94

Biller S, Mosier A, Wells G, Francis C (2012) Global biodiversity of aquatic ammonia-oxidizing archaea is partitioned by habitat. Front Microbiol 3:252 
Borcard D, Gillet R, Legendre P (2011) Numerical ecology with R. Springer, New York, NY

- Bouskill NJ, Eveillard D, Chien DM, Jayakumar A, Ward BB (2012) Distribution and abundance of ammonia-oxidizing organisms across environmental gradients. Environ Microbiol 14:714-729

Braker G, Fesefeldt A, Witzel KP (1998) Development of PCR primer systems for amplification of nitrite reductase genes (nirK and nirS) to detect denitrifying bacteria in environmental samples. Appl Environ Microbiol 64: 3769-3775

Bulow SE, Francis CA, Jackson GA, Ward BB (2008) Sediment denitrifier community composition and nirS gene expression investigated with functional gene microarrays. Environ Microbiol 10:3057-3069

Bulow SE, Rich JJ, Naik HS, Pratihary AK, Ward BB (2010) Denitrification exceeds anammox as a nitrogen loss pathway in the Arabian Sea oxygen minimum zone. DeepSea Res I 57:384-393

> Carpenter JH (1965) The Chesapeake Bay Institute technique for the Winkler dissolved oxygen method. Limnol Oceanogr 10:141-143

Casciotti KL, Buchwald C, Santoro AE, Frame C (2011) Assessment of nitrogen and oxygen isotopic fractionation during nitrification and its expression in the marine environment. In: Klotz MG (ed) Methods in enzymology: research on nitrification and related processes, Vol 486. Elsevier Academic Press, San Diego, CA, p 253-280

Codispoti LA, Friederich GE, Packard TT, Glover HE and others (1986) High nitrite levels off northern Peru: a signal of instability in the marine denitrification rate. Science 233:1200-1202

Dalsgaard T, Thamdrup B, Farias L, Revsbech NP (2012) Anammox and denitrification in the oxygen minimum zone of the eastern South Pacific. Limnol Oceanogr 57: 1331-1346

Devol AH (2008) Denitrification, including anammox. In: Capone DG, Bronk DA, Mulholland MR, Carpenter EJ (eds) Nitrogen in the marine environment. Elsevier, Amsterdam, p 263-301

Ducklow HW (1993) Bacterioplankton distributions and production in the Northwestern Indian Ocean and Gulf of Oman, September, 1986. Deep-Sea Res 40:753-771

Francis CA, O'Mullan GD, Cornwell JC, Ward BB (2013) Transitions in nirS-type denitrifier diversity, community composition, and biogeochemical activity along the Chesapeake Bay estuary. Front Microbiol 4, Article 237, August 2013, doi:10.3389/fmicb.2013.00237

Galan A, Molina V, Thamdrup B, Woebken D, Lavik G, Kuypers MMM, Ulloa O (2009) Anammox bacteria and the anaerobic oxidation of ammonium in the oxygen minimum zone off northern Chile. Deep-Sea Res II 56: 1021-1031

Grasshof K, Ehrhardt M, Kremling K (1983) Methods of seawater analysis, 2nd edn. Verlag Chemie, Weinheim

> Hamersley MR, Lavik G, Woebken D, Rattray JE and others (2007) Anaerobic ammonium oxidation in the Peruvian oxygen minimum zone. Limnol Oceanogr 52:923-933

Jayakumar DA, Francis CA, Naqvi SWA, Ward BB (2004) Diversity of nitrite reductase genes (nirS) in the denitrifying water column of the coastal Arabian Sea. Aquat Microb Ecol 34:69-78

Jayakumar A, Naqvi SWA, Ward BB (2009a) Distribution and relative quantification of key genes involved in fixed nitrogen loss from the Arabian Sea oxygen mini- mum zone. In: Wiggert JD, Hood RR (eds) Indian Ocean biogeochemical processes and ecological variability. American Geophysical Union, Washington, DC, p $187-203$

> Jayakumar A, O'Mullan GD, Naqvi SWA, Ward BB (2009b) Denitrifying bacterial community composition changes associated with stages of denitrification in oxygen minimum zones. Microb Ecol 58:350-362

Kalvelage T, Lavik G, Lam P, Contreras S and others (2013) Nitrogen cycling driven by organic matter export in the South Pacific oxygen minimum zone. Nat Geosci 6: 228-234

Lam P, Lavik G, Jensen MM, van de Vossenberg J and others (2009) Revising the nitrogen cycle in the Peruvian oxygen minimum zone. Proc Natl Acad Sci USA 106: 4752-4757

> Morrison JM, Codispoti LA, Smith SL, Wishner K and others (1999) The oxygen minimum zone in the Arabian Sea during 1995. Deep-Sea Res II 46:1903-1931

$>$ Newell SE, Babbin AR, Jayakumar A, Ward BB (2011) Ammonia oxidation rates and nitrification in the Arabian Sea. Global Biogeochem Cycles 25:GB4016, doi:10.1029/ 2010GB003940

Nicholls JC, Davies IM, Trimmer M (2007) High-resolution profiles and nitrogen isotope tracing reveal a dominant source of nitrous oxide and multiple pathways of nitrogen gas formation in the central Arabian Sea. Limnol Oceanogr 52:156-168

Paulmier A, Ruiz-Pino D (2009) Oxygen minimum zones (OMZs) in the modern ocean. Prog Oceanogr 80:113-128

- Pester M, Rattei G, Flechi S, Grongroft A and others (2012) amoA-based consensus phylogeny of ammonia-oxidizing archaea and deep sequencing of amoA genes from soils of four different geographic regions. Environ Microbiol 14:525-539

- Revsbech NP, Larsen LH, Gundersen J, Dalsgaard T, Ulloa O, Thamdrup B (2009) Determination of ultra-low oxygen concentrations in oxygen minimum zones by the STOX sensor. Limnol Oceanogr Methods 7:371-381

> Santoro AE, Boehm AB, Francis CA (2006) Denitrifier community composition along a nitrate and salinity gradient in a coastal aquifer. Appl Environ Microbiol 72: 2102-2109

Schmid M, Walsh KA, Webb R, Rijpstra WIC and others (2003) Candidatus 'Scalindua broda', sp. nov., Candidatus 'Scalindua wagneri', sp. nov., two new species of anaerobic ammonia oxidizing bacteria. Syst Appl Microbiol 26:529-538

Schmid MC, Risgaard-Petersen N, van de Vossenberg J, Kuypers MMM and others (2007) Anaerobic ammoniumoxidizing bacteria in marine environments: widespread occurrence but low diversity. Environ Microbiol 9: 1476-1484

Smith CJ, Nedwell DB, Dong LF, Osborn AM (2006) Evaluation of quantitative polymerase chain reaction-based approaches for determining gene copy and gene transcript numbers in environmental samples. Environ Microbiol 8:804-815

Spinrad RW, Glover HE, Ward BB, Codispoti LA, Kullenberg G (1989) Suspended particle and bacterial maxima in Peruvian coastal waters during a cold water anomaly. Deep-Sea Res 36:715-733

Stevens H, Ulloa O (2008) Bacterial diversity in the oxygen minimum zone of the eastern tropical South Pacific. Environ Microbiol 10:1244-1259 
Stewart FJ, Ulloa O, DeLong EF (2012) Microbial metatranscriptomics in a permanent marine oxygen minimum zone. Environ Microbiol 14:23-40

Thamdrup B, Dalsgaard T, Revsbech NP (2012) Widespread functional anoxia in the oxygen minimum zone of the Eastern South Pacific, Deep-Sea Res I 65:36-45

Throbäck IN, Enwall K, Jarvis A, Hallin S (2004) Reassessing PCR primers targeting nirS, nirK and nosZ genes for community surveys of denitrifying bacteria with DGGE. FEMS Microbiol Ecol 49:401-417

van de Vossenberg J, Woebken D, Maalcke W, Wessels HJCT and others (2013) The metagenome of the marine anammox bacterium 'Candidatus Scalindua profunda' illustrates the versatility of this globally important nitrogen cycle bacterium. Environ Microbiol 15:1275-1289

van der Star WRL, Miclea AI, Van Dongen UGJM, Muyzer G, Picioreanu C, Van Loosdrecht MCM (2008) The membrane bioreactor: a novel tool to grow anammox bacteria as free cells. Biotechnol Bioeng 101:286-294

> Varela MM, van Aken HM, Sintes E, Reinthaler T, Herndl GJ (2011) Contribution of Crenarchaeota and Bacteria to autotrophy in the North Atlantic interior. Environ Micro-

Editorial responsibility: Douglas Capone,

Los Angeles, California, USA biol 13:1524-1533

Ward BB, Bouskill NJ (2011) The utility of functional gene arrays for assessing community composition, relative abundance, and distribution of ammonia-oxidizing bacteria and archaea. Methods Enzymol 496: 373-396

Ward BB, Tuit CB, Jayakumar A, Rich JJ, Moffett J, Naqvi SWA (2008) Organic carbon, and not copper, controls denitrification in oxygen minimum zones of the ocean. Deep-Sea Res I 55:1672-1683

> Ward BB, Devol AH, Rich JJ, Chang BX and others (2009) Denitrification as the dominant nitrogen loss process in the Arabian Sea. Nature 461:78-81

- Woebken D, Lam P, Kuypers MMM, Naqvi SWA and others (2008) A microdiversity study of anammox bacteria reveals a novel Candidatus Scalindua phylotype in marine oxygen minimum zones. Environ Microbiol 10: 3106-3119

Zimmerman GM, Goetz H, Mielke PW (1985) Use of an improved statistical method for group comparisons to study effects of prairie fire. Ecology 66:606-611

Zumft WG (1997) Cell biology and molecular basis of denitrification. Microbiol Mol Biol Rev 61:533-616

Submitted: March 26, 2013; Accepted: July 9, 2013

Proofs received from author(s): September 20, 2013 